\title{
Smoking and Health-Related Quality of Life (SF-36). A Population-Based Study in Campinas, SP, Brazil
}

\author{
Margareth Guimarães Lima*, Flávia Silva Arbex Borim, Marilisa Berti de Azevedo Barros \\ Faculty of Medical Sciences, Department of Public Health, State University of Campinas, Campinas, Brazil \\ Email: ${ }^{\text {margarethglima@gmail.com }}$
}

Received 21 April 2014; revised 31 May 2014; accepted 20 June 2014

Copyright (C) 2014 by authors and Scientific Research Publishing Inc.

This work is licensed under the Creative Commons Attribution International License (CC BY).

http://creativecommons.org/licenses/by/4.0/

(c) (i) Open Access

\begin{abstract}
Introduction: Smoking persists as a global and relevant health problem being one of the major risk factors to non-communicable diseases and early death. Studies on the association between smoking and health related quality of life (HRQL) are scarce in Brazil and Latin America. The aim of this study was to analyze the HRQL according to smoking status on adults aged 20 to 59 years, living in Campinas, Brazil. Method: It is a population-based cross-sectional study, carried out with data from the Campinas Health Survey developed in 2008/2009. The dependent variables were the eight scales and the two components-physical (PCS) and mental component summary (MCS) of the instrument SF-36, version 2. Means and confidence intervals of the SF-36 scale scores and components were estimated according to smoking (never smokers, former smokers, current smokers) and nicotine dependence (mild, moderate, heavy). Results: The sample comprised 957 individuals (mean age of $\mathbf{3 7 . 5}$ years). Comparing with never smokers, smokers had lower score means in all SF-36 scales, except in physical functioning and role-physical; among the former smokers, lower scores were observed in vitality and mental health. A reduction of the MCS score was observed among smokers and former smokers among men; but in the female population, this reduction was observed only in smokers compared with never smokers. According to the nicotine dependence, it was observed an increasing reduction in MCS scores from mild, to moderate and heavy smokers. Conclusion: Smoking is significantly and negatively associated with HRQL in the studied population. The results point out the importance of the strategic policies against smoking, to reduce morbidity and premature death, but also to increase the quality of life and well-being. It is also important to consider the mental health dimension, since that best mental health can be relevant to promote healthier behaviors.
\end{abstract}

\section{Keywords}

Smoking, Quality of Life, Health Status, SF-36, Survey

\footnotetext{
${ }^{*}$ Corresponding author.
}

How to cite this paper: Lima, M.G., Borim, F.S.A. and de Azevedo Barros, M.B. (2014) Smoking and Health-Related Quality of Life (SF-36). A Population-Based Study in Campinas, SP, Brazil. Health, 6, 1539-1548. 


\section{Introduction}

Smoking persists as one of the major public health problems, being recognized by undeniable evidences as one of the leading risk factors for chronic diseases and early death. The World Health Organization (WHO) estimates that $8.7 \%$ of deaths occurring worldwide can be attributed to tobacco consumption [1] and that, every year, smoking brings on 6 million deaths, a number that shall rise to 7.5 in 2020 and 8 million in 2030, with most of these deaths occurring in low-and middle-income countries [2]. In relation to non-communicable diseases (NCDs), according to the World Health Organization [2], tobacco use is responsible for $71 \%$ of occurrences of lung cancer, $42 \%$ of chronic respiratory diseases, and $10 \%$ of cardiovascular diseases.

The interventions for reducing cigarette consumption are important. In Canada, the intention to quit smoking before the introduction of smoking reduction programs was $20 \%$, rising to $87 \%$ after interventions [3]. Anti-tobacco policies are carried out in $46 \%$ of the countries, however, only 19 countries intervene more efficiently [3]. Among the main Brazilian policies for smoking reduction, features the ban on cigarettes advertisements, the warnings about the risk of health problems on the packs of the product, the adherence to the Framework Convention on Tobacco Control in 2006 [4].

One of the important goals of the Brazilian strategic actions plan to combat chronic non-communicable disease-2011/2022 is to reduce the prevalence of smoking in adults. According to the plan, it is expected an average decrease of $3.4 \%$ per year over the period from 2006 to 2022 [4]. The prevalence of smoking in the Brazilian adult population is $15.1 \%$, and both the prevalence and the smoking cessation tend to differ between sexes, with the highest occurrence of tobacco consumption among men [5]. The highest prevalence is observed in the group from 18 to 29 years old in men and from 30 to 59 years old in women [6]. The study by Silva et al. (2011) [6], with data from 27 Brazilian capitals, presented the tendency of smoking between the years 2006 and 2009, by sex, revealing a small decrease in the prevalence among men, and a tendency to stabilize among women. It also was observed an increase in smoking cessation of $3 \%$ in the male population, while among women, the percentage of cessation was negative $(-5.5 \%)$.

Besides the obvious damage of smoking on mortality and incidence of the disease, it is important to evaluate the relationship of smoking with positive aspects of health, as functional capacity, well-being, social relationships, mental health, considering that, besides the disease, the health and well-being shall also be an important focus of health policies [7]-[9]. The Medical Outcomes Study 36-Item Short-Form (SF-36) is an instrument for measuring the health status and health-related quality of life (HRQoL), which assesses eight dimensions of health. The instrument was submitted to validation in Brazil [10] and is widely used internationally [7] [11] [12].

The association of smoking with the different dimensions of health has been assessed in some countries, and the research results indicate that current smokers are in worse health conditions and HRQoL compared with individuals who never smoked [13]-[17]. Although this association is present in several health dimensions, it can be verified, in the results of some researches, a stronger association of smoking with mental dimension [14] [17]-[19]. The associations, comparing individuals who had never smoked with ex-smokers, were weaker or did not exist, indicating the positive effect of smoking cessation [17] [20]-[22]. The research results also showed major damage to health and in the HRQoL of smokers, with the increase of nicotine dependence [19] [21]-[24]. Although studies regarding the association between smoking and HRQoL are scarce according to sex, Heikkinen et al. (2007) [22] found a greater association among men than among women.

The researches on smoking and HRQoL conducted in Brazil [17], in Latin America and in less developed countries are scarce, hindering understanding the relation between smoking and HRQoL in least advantaged areas.

This research aims to analyze the association of smoking and the nicotine dependence level, with the eight dimensions and the two components of health status and health-related quality of life, assessed with the SF-36, in the adult population of Campinas, SP, Brazil.

\section{Material and Method}

This study was developed with data from the population-based health survey carried out in 2008/2009 in the city of Campinas (ISACamp 2008), which collected information from non-institutionalized individuals living in the urban area of the city. 


\subsection{The Sampling Process in ISA-Camp 2008}

The survey addressed three population subgroups: adolescents, adults and elderly (10 to 19 years old, 20 to 59 years old and 60 years or older). Samples of 1000 individuals from each age group were obtained. With this sample size it is possible to estimate a prevalence of 0.50 , which corresponds to the maximum variability for the frequency of events studied, with a confidence level of 95\%, sampling error between 4 and 5 percentage points, and considering a design effect equal to 2 .

The cluster sampling was obtained in two stages. In the first stage, 50 census tracts were selected proportional to the number of households. It was established that 50 sectors would be drawn, considering that the total interviews from each age domain, by sector, should not exceed 20. In the second stage, a random of households were selected within the sectors that had been drawn.

The calculation of the number of households to be drawn was made from the expected average number of people per household (ratio people/households) of each age group. Predicting the occurrence of loss, 20\% more households were randomly selected, increasing the household sample sizes to 2150, 700 and 3900 corresponding to the three age groups.

More details about the sampling process are available on the website of the Collaborative Center on Health Situation Analysis (CCAS).

\subsection{Data Collection Instrument}

Information was collected using a questionnaire applied by trained interviewers and responded directly by the selected individuals. The variables analyzed in this study were:

The eight scales and the two components of The Medical Outcomes Study 36-item Short-Form-SF-36, version 2 (SF-36) v2: The scales that compose the SF-36 were analyzed as dependent variables, namely: physical functioning, role physical, pain, general health, vitality, role-emotional, social functioning and mental health. Also as dependent variables the two components of measurement that summarize the scales were analyzed: physical component summary (PCS) and mental component summary (MCS). The PCS is composed by physical functioning, role-physical and pain, while role-emotional, social functioning and mental health scales compose the MCS. The vitality and general health are part of both components.

The total score obtained in each of the eight scales (domains) were converted into a scale from 0 to 100 [7]. Zero corresponds to the worst health status and 100 to the best. The component scales are presented in z-scores, which are standardized in relation to the American population (average of 50 and a standard deviation of 10), and constructed by means of factor analysis. According to the SF-36 developers, if the SF-36 mean scales of the population are displayed, it is used to calculate the component scales [25]. However, this average of reference is not yet available for the Brazilian population.

Smoking: Categorized into current smoker, ex-smoker and never smoker. Were considered ex-smokers people who reported having smoked at least 100 cigarettes in life and had stopped with the consumption; were classified as smokers, those who persisted with tobacco consumption at the time of the interview.

Nicotine dependence: The Fagerström Test [26] were used with the following cut-off points for constructing the categories: mild dependence-for smokers who have had up to 4 positive responses on the test; moderate dependence- 5 to 7 positive responses; heavy dependence-those who have had 8 or more positive responses.

Demographic characteristics: gender (male and female) and age group (20-29/30-39/40-49/50-59).

Number of reported chronic morbidities, categorized as: none, 1, and 2 or more.

\subsection{Data Analysis}

The survey data were entered into a database developed with the software Epi Data, version 3.1 and submitted for evaluation of consistency. The prevalence of smokers and non-smokers according to age, gender and number of diseases were estimated. The associations between those variables and smoking and nicotine dependence were analyzed by the chi-square test. Were also estimated the mean scores of the SF-36 and the respective confidence intervals according to smoking and nicotine dependence. To determine the association of the scales and the components of the SF-36 with tobacco consumption and nicotine dependence were conducted models of simple and multiple linear regression (with adjustments by gender, age and number of chronic diseases), for each of the 8 scales and the 2 components. Analyzes were also conducted with stratification by gender. For the statistical 
treatment, the Svy Commands of STATA version 11.0 software were employed, using the weights derived from the sampling design and considering the existing primary sampling units (PSUs).

\subsection{Ethical Procedures}

The ISA-Camp 2008 was approved by the Research Ethics Committee of the Faculty of Medical Sciences of the State University of Campinas, Brazil, under protocol no. 079/2007. All participants signed a free informed consent form.

\section{Results}

The studied population consisted of 957 adults, with an average of 37.5 years old (CI 95\%: 36.6 - 38.3). The female population corresponds to 51.3\% (CI 95\%: 48.7 - 54.0). The presence of one chronic disease was observed in 24.1\% (CI 95\%: 20.9 - 27.2) of the studied individuals and 12.7\% (CI 95\%: 10.0 - 15.2) present two or more diseases. 20.6\% (CI 95\%:17.5 - 23.8) of the studied population are current smokers and 11.4\% (CI 95\%: 8.3 - 14.5) are ex-smokers. Among the smokers, 26.7\% (95\% CI: 20.0 - 33.4) consumes less than 10 cigarettes a day and 41.6\% (95\% CI: 35.1 - 48.0) 20 cigarettes or more. Among the ex-smokers, 19.4\% (CI 95\%: 11.8 - 27.0) quit smoking less than two years ago and 48.5\% (CI 95\%: 37.3 - 59.7) more than 10 years ago (not in the table).

The women, in higher percentage, never smoked and men showed the highest prevalence of smokers or ex-smokers (Table 1). The higher proportion of smoker and former smoker is observed in older individuals. The prevalence of smokers and individuals with moderate nicotine dependence is higher among those with greatest number of chronic diseases. Most of the ex-smokers population smoked 20 cigarettes or more per day (54.5\% [CI 95\%: 45.0 - 63.7]), and the percentage is significantly higher among men (64.3\%). 37.7\% of the women smoked less than 10 cigarettes per day, while this quantity of cigarettes was consumed by $7.9 \%$ of ex-smokers male population (not in the table).

The SF-36 mean scale scores differ according to smoking conditions (Table 2). Compared to individuals who had never smoked, ex-smokers have lower mean scores in pain, general health, vitality and mental health, and in the MCS. Smokers have lowered mean scores in all SF-36 scales, except for the PCS, in the physical functioning. In the analysis adjusted by gender, age and number of chronic diseases, the vitality and mental health scales and the MCS are impaired in individuals who quit smoking compared with those who never smoked. However, on those who continue smoking, all scales, with the exception of physical functioning, role physical and PCS, remain with lower mean scores, with the greatest magnitude of reduction in mental health $(\beta=-7.7)$ and vitality $(\beta=-5.7)$.

Table 3 shows the SF-36 mean scores for individuals who have never smoked and for current smokers with different degrees of nicotine dependence (mild, moderate and heavy dependence). In the adjusted analysis, those with mild dependence are with the lowest mean scores in social functioning $(\beta=-5.2)$, mental health $(\beta=-6.8)$ and the MCS $(\beta=-3.2)$, compared with never smokers. Individuals with moderate dependence present decreased averages scores in general health $(\beta=-6.6)$, vitality $(\beta=-5.4)$ mental health $(\beta=-7.5)$ and MCS $(\beta=$ -2.8 ). The largest magnitudes of scores reduction, however, are observed considering individuals with heavy dependence, on the scales of pain $(\beta=-12.4)$, vitality $(\beta=-13.2)$ role-emotional $(\beta=-9.4)$ and mental health $(\beta$ $=-10.7)$. The MCS of this population is heavily damaged, compared with never smokers $(\beta=-6.2)$.

Associations between smoking and health-related quality of life differ according to gender. In the male population, after adjusting by age, gender and number of chronic diseases, the mean scale scores of general health, vitality, mental health, and MCS scales are lower among ex-smokers and smokers, compared with never smokers. The higher reductions in scores are observed in ex-smokers. In the female population, however, the condition of ex-smokers was not associated with worse quality of life in any of the SF-36 scales, whereas women smokers have lowest mean scores in pain, general health, vitality, role-emotional, mental health, and in the MCS (Table 4).

\section{Discussion}

The results of the study show the association among HRQoL, using the SF-36, and smoking, in the adult population of the city of Campinas, SP. Studies on the topic have been developed in European countries [13] [14] [19] [20] [22] [27] [28] and in the United States [14] [18] [16] [29], however there is no such population-based study, with the adult population, in Brazil and in Latin America. The only research that evaluated the HRQoL 
Table 1. Smoking by gender, age and number of chronic disease in adult population (20 to 60 years old) of Campinas, SP, Brazil. ISACAMP 2008.

\begin{tabular}{|c|c|c|c|c|c|}
\hline \multicolumn{6}{|c|}{ Prevalence (\%) } \\
\hline & $\mathrm{n}$ & $\begin{array}{c}\text { Never smoker } \\
n=638\end{array}$ & $\begin{array}{l}\text { Former smoker } \\
\qquad \mathrm{n}=110\end{array}$ & $\begin{array}{l}\text { Smoker } \\
\mathrm{n}=197\end{array}$ & p Value \\
\hline Gender & & & & & 0.0042 \\
\hline Male & 448 & $63.2(57.5-68.6)$ & $24.8(20.9-29.1)$ & $12.0(9.1-15.5)$ & \\
\hline Female & 507 & $72.4(65.9-72.7)$ & $16.7(13.1-21.0)$ & $10.8(7.4-15.6)$ & \\
\hline Age & & & & & 0.0002 \\
\hline 20 to 29 & 280 & $77.6(72.8$ - 81.9) & $15.5(11.8$ - 19.9) & $6.9(4.1-11.3)$ & \\
\hline 30 to 39 & 246 & $69.3(61.0$ - 76.6) & $20.5(14.6-28.0)$ & $10.1(64.0-15.6)$ & \\
\hline 40 to 49 & 418 & $60.2(53.1-66.9)$ & $24.6(20.6-29.2)$ & $15.1(11.2-20.2)$ & \\
\hline Number or chronic disease & & & & & 0.0000 \\
\hline 0 & 595 & $73.0(68.8-76.8)$ & $20.0(17.2-23.2)$ & $7.0(4.9-10.1)$ & \\
\hline 1 & 228 & $63.3(54.0-71.7)$ & $21.1(15.4-28.3)$ & $15.6(10.2-23.1)$ & \\
\hline 2 and more & 122 & $52.1(40.6-63.4)$ & $23.1(15.3-33.3)$ & $24.9(17.3-34.3)$ & \\
\hline \multicolumn{6}{|c|}{ Nicotine dependence } \\
\hline & & $\begin{array}{l}\text { Mild } \\
\mathrm{n}=93\end{array}$ & $\begin{array}{c}\text { Moderate } \\
\mathrm{n}=71\end{array}$ & $\begin{array}{l}\text { Heavy } \\
\mathrm{n}=32\end{array}$ & \\
\hline Gender & & & & & 0.8350 \\
\hline Male & & $46.3(35.3-57.8)$ & $37.6(28.0-48.2)$ & $16.1(9.8-25.4)$ & \\
\hline Female & & $49.6(40.8-58.3)$ & $33.6(24.6-44.1)$ & $16.8(10.6-25.6)$ & \\
\hline Age & & & & & 0.1318 \\
\hline 20 to 29 & & $55.9(38.1-72.3)$ & $29.1(15.2-48.6)$ & $15.0(6.6-30.3)$ & \\
\hline 30 to 39 & & $58.3(44.0-71.3)$ & $24.8(14.9-38.2)$ & $17.0(8.4-31.1)$ & \\
\hline 40 to 49 & & $38.7(29.9-48.3)$ & $44.5(34.2-55.2)$ & $16.8(10.8-25.2)$ & \\
\hline Number or chronic disease & & & & & 0.0001 \\
\hline 0 & & $53.9(44.1-63.5)$ & $34.1(24.7-45.0)$ & $11.9(6.8-20.2)$ & \\
\hline 1 & & $45.5(33.2-58.5)$ & $21.3(11.9-35.2)$ & $33.2(20.7-48.6)$ & \\
\hline 2 and more & & $24.4(12.9$ - 41.2) & $68.1(49.5$ - 82.3) & $7.6(1.9-25.9)$ & \\
\hline
\end{tabular}

Table 2. Mean of the SF-36 score scale and adjusted beta coefficients according to smoking in the 20 to 60 years age population. Campinas, SP. ISACAMP 2008.

\begin{tabular}{cccccc}
\hline & \multicolumn{4}{c}{ Crude analysis } & \multicolumn{2}{c}{ Adjusted analysis $^{*}$} \\
\cline { 2 - 6 } SF-36 scales & \multicolumn{3}{c}{ Mean scale scores and p value } & Beta coefficients and p values \\
\cline { 2 - 6 } & $\begin{array}{c}\text { Never smoker }(1) \\
\mathrm{n}=648\end{array}$ & $\begin{array}{c}\text { Former smoker }(2) \\
\mathrm{n}=110\end{array}$ & $\begin{array}{c}\text { Smoker }(3) \\
\mathrm{n}=197\end{array}$ & $2-1$ & $3-1$ \\
\hline Physical functioning & 94.2 & $92.4(0.448)$ & $92.8(0.274)$ & $0.7(0.678)$ & $-0.5(0.665)$ \\
Role-physical & 95.1 & $91.3(0.110)$ & $92.1(0.033)$ & $-0.9(0.667)$ & $-2.4(0.074)$ \\
Bodily pain & 89.5 & $81.6(0.015)$ & $84.1(0.006)$ & $-4.3(0.112)$ & $-4.4(0.007)$ \\
General health & 82.7 & $76.6(0.014)$ & $77.5(0.001)$ & $-3.4(0.216)$ & $-4.1(0.002)$ \\
Vitality & 80.5 & $71.0(0.002)$ & $74.5(0.000)$ & $-6.5(0.024)$ & $-5.7(0.001)$ \\
Role-emotional & 95.8 & $91.9(0.094)$ & $91.3(0.005)$ & $-2.1(0.314)$ & $-3.9(0.008)$ \\
Social functioning & 93.1 & $88.7(0.101)$ & $89.5(0.020)$ & $-1.6(0.505)$ & $-3.3(0.026)$ \\
Mental health & 82.5 & $74.2(0.008)$ & $74.5(0.000)$ & $-5.6(0.050)$ & $-7.7(0.000)$ \\
PCS & 56.0 & $54.5(0.096)$ & $55.3(0.149)$ & $-0.2(0.763)$ & $-0.3(0.449)$ \\
MCS & 55.0 & $51.1(0.010)$ & $51.3(0.000)$ & $-2.7(0.052)$ & $-3.5(0.000)$ \\
\hline
\end{tabular}

*Adjusted by gender, age and number of chronic disease. 
Table 3. Mean of the SF-36 score scale and beta coefficients according to nicotine dependence (Fagerström test) in the 20 to 60 years age population. Campinas, SP. ISACAMP 2008.

\begin{tabular}{|c|c|c|c|c|}
\hline \multirow{3}{*}{ SF-36 scales } & \multicolumn{4}{|c|}{ Mean scale scores, beta coefficients and p value } \\
\hline & \multirow[b]{2}{*}{ Never smoker } & \multicolumn{3}{|c|}{ Smoker-Nicotine dependence } \\
\hline & & $\begin{array}{c}\text { Mild } \\
\mathrm{n}=93\end{array}$ & $\begin{array}{c}\text { Moderate } \\
\mathrm{n}=71\end{array}$ & $\begin{array}{l}\text { Heavy } \\
\mathrm{n}=32\end{array}$ \\
\hline & \multicolumn{4}{|c|}{ Mean scale scores and p value. Crude analysis } \\
\hline Physical functioning & 94.2 & $94.7(0.576)$ & $88.9(0.035)$ & $93.5(0.719)$ \\
\hline Role-physical & 95.1 & $93.5(0.302)$ & $90.1(0.055)$ & $92.3(0.414)$ \\
\hline Bodily pain & 89.5 & $85.7(0.016)$ & $85.0(0.232)$ & $76.6(0.011)$ \\
\hline General health & 82.7 & $79.9(0.137)$ & $74.1(0.005)$ & $78.9(0.277)$ \\
\hline Vitality & 80.5 & $77.6(0.190)$ & $73.9(0.018)$ & $66.7(0.000)$ \\
\hline Role-emotional & 95.8 & $93.1(0.128)$ & $90.8(0.060)$ & $86.6(0.043)$ \\
\hline Social functioning & 93.1 & $88.8(0.034)$ & $90.2(0.322)$ & $89.7(0.293)$ \\
\hline Mental health & 82.5 & $76.1(0.003)$ & $73.8(0.006)$ & $71.3(0.002)$ \\
\hline PCS & 56.0 & $55.9(0.988)$ & $54.1(0.065)$ & $55.5(0.653)$ \\
\hline MCS & 55.0 & $52.1(0.012)$ & $51.6(0.022)$ & $48.8(0.001)$ \\
\hline Mean scores & Mean scores & \multicolumn{3}{|c|}{ Beta coefficients and $\mathrm{p}$ values. Adjusted analysis ${ }^{*}$} \\
\hline Physical functioning & 94.2 & $0.6(0.649)$ & $-2.9(0.139)$ & $1.4(0.505)$ \\
\hline Role-physical & 95.1 & $-2.0(0.224)$ & $-2.8(0.219)$ & $-2.3(0.492)$ \\
\hline Bodily pain & 89.5 & $-4.4(0.067)$ & $-1.0(0.695)$ & $-12.4(0.015)$ \\
\hline General health & 82.7 & $-3.0(0.103)$ & $-6.6(0.007)$ & $-2.8(0.411)$ \\
\hline Vitality & 80.5 & $-3.5(0.114)$ & $-5.4(0.034)$ & $-13.2(0.000)$ \\
\hline Role-emotional & 95.8 & $-2.8(0.102)$ & $-3.0(0.118)$ & $-9.4(0.034)$ \\
\hline Social functioning & 93.1 & $-5.2(0.008)$ & $-0.8(0.719)$ & $-3.2(0.327)$ \\
\hline Mental health & 82.5 & $-6.8(0.001)$ & $-7.5(0.005)$ & $-10.7(0.001)$ \\
\hline PCS & 56.0 & $-0.1(0.255)$ & $-0.7(0.344)$ & $-0.4(0.892)$ \\
\hline MCS & 55.0 & $-3.2(0.005)$ & $-2.8(0.020)$ & $-6.2(0.001)$ \\
\hline
\end{tabular}

*Adjusted by gender, age and number of chronic disease.

according to smoking, in population-based in Brazil, was the one by Lima et al. (2011) in 4 regions of the State of São Paulo. However, the research analyzed only the elderly population [17].

According to this study, the higher percentage of smokers, especially those with moderate nicotine dependence, was observed among individuals with higher number of chronic diseases. Individuals with high dependence are not those with greater number of illnesses, possibly considering that the emergence of chronic diseases tends to cause the smoking cessation.

Considering the associations of the HRQoL with smoking, the smoker individuals and former smokers are with the lowest SF-36 mean scale scores in relation to individuals who have never smoked, considering the total population from 20 to 59 years old. Compared to smokers, the MCS and all dimensions evaluated using the SF-36, except for physical functioning and role-physical, presented significantly lower scores in the adjusted analysis. The biggest differences between the average scores were observed in mental health and vitality. Other authors also observed worst ratings of the dimensions in smokers [13]-[17] [20]. As in the present study, the largest damage to the MCS was observed by Guiterrez-Bedmar et al. (2009) [19], with 5.234 adults in Spain, who found the lowest scores in smokers, in the scales of general health, social functioning, role emotional and mental health. In the study by Lima et al. (2011) [17], with 1958 elderly people in Brazil, the worst health conditions were observed on the role emotional and mental health scales. In other researches, the mental health dimension also proved in worse conditions in smokers [14] [18]. According to Diez et al. study (2010) [28], in the city of Madrid, compared to nonsmokers, smokers consumes more antidepressants and tranquilizers, drink more alcohol beverage and practice less physical activity.

Comparing former smokers with never smokers, there was a significant reduction of the mean scores of vitality and mental health scales among ex-smokers. Wilson et al. (1994) [23], with representative data from the 
Table 4. Mean of the SF-36 score scale and adjusted beta coefficients according to smoking in the adult (20 to 60 years age) population, by gender. Campinas, SP.

\begin{tabular}{|c|c|c|c|c|c|}
\hline \multirow{3}{*}{ SF-36 scales } & \multicolumn{3}{|c|}{ Crude analysis } & \multicolumn{2}{|c|}{ Adjusted analysis } \\
\hline & \multicolumn{3}{|c|}{ Mean scale scores and p value } & \multicolumn{2}{|c|}{ Beta coefficients and $p$ values } \\
\hline & Never smoker (1) & Former smoker (2) & Smoker (3) & $2-1^{*}$ & $3-1^{*}$ \\
\hline & \multicolumn{5}{|c|}{ Male } \\
\hline Physical functioning & 95.2 & $90.0(0.162)$ & $95.7(0.911)$ & $2.8(0.143)$ & $-0.4(0.790)$ \\
\hline Role-physical & 96.1 & $92.8(0.113)$ & $92.7(0.220)$ & $0.1(0.974)$ & $-1.5(0.431)$ \\
\hline Bodily pain & 92.6 & $86.7(0.066)$ & $83.5(0.010)$ & $-5.8(0.084)$ & $-3.6(0.139)$ \\
\hline General health & 84.3 & $79.9(0.046)$ & $74.8(0.003)$ & $-6.9(0.026)$ & $-3.7(0.040)$ \\
\hline Vitality & 83.8 & $76.9(0.002)$ & $70.6(0.000)$ & $-10.9(0.001)$ & $-5.6(0.007)$ \\
\hline Role-emotional & 97.0 & $92.2(0.030)$ & $93.2(0.177)$ & $-1.9(0.474)$ & $-3.0(0.093)$ \\
\hline Social functioning & 94.9 & $91.1(0.063)$ & $91.1(0.182)$ & $-1.6(0.526)$ & $-3.1(0.094)$ \\
\hline Mental health & 86.1 & $76.3(0.000)$ & $74.7(0.000)$ & $-9.0(0.001)$ & $-8.8(0.000)$ \\
\hline PCS & 56.3 & $55.7(0.407)$ & $55.1(0.213)$ & $0.04(0.967)$ & $-0.1(0.907)$ \\
\hline \multirow[t]{2}{*}{ MCS } & 56.6 & $52.4(0.000)$ & $51.3(0.001)$ & $-4.3(0.003)$ & $-3.7(0.000)$ \\
\hline & \multicolumn{5}{|c|}{ Female } \\
\hline Physical functioning & 93.8 & $90.0(0.125)$ & $92.6(0.402)$ & $-1.0(0.585)$ & $-0.5(0.748)$ \\
\hline Role-physical & 94.8 & $89.7(0.091)$ & $90.1(0.030)$ & $-1.2(0.652)$ & $-3.6(0.060)$ \\
\hline Bodily pain & 87.6 & $79.4(0.036)$ & $80.2(0.000)$ & $-2.1(0.518)$ & $-5.4(0.007)$ \\
\hline General health & 81.1 & $75.5(0.164)$ & $74.0(0.002)$ & $-0.4(0.990)$ & $-4.4(0.038)$ \\
\hline Vitality & 77.7 & $70.8(0.075)$ & $69.8(0.002)$ & $-2.2(0.525)$ & $-5.9(0.025)$ \\
\hline Role-emotional & 95.0 & $90.4(0.139)$ & $89.1(0.005)$ & $-2.2(0.415)$ & $-5.0(0.013)$ \\
\hline Social functioning & 91.6 & $86.0(0.102)$ & $87.1(0.070)$ & $-1.2(0.672)$ & $-3.5(0.187)$ \\
\hline Mental health & 79.9 & $73.7(0.164)$ & $71.8(0.002)$ & $-2.0(0.628)$ & $-6.4(0.013)$ \\
\hline PCS & 55.8 & $53.6(0.047)$ & $54.5(0.037)$ & $-0.3(0.797)$ & $-0.8(0.196)$ \\
\hline MCS & 53.8 & $50.7(0.150)$ & $49.7(0.002)$ & $-1.1(0.563)$ & $-3.3(0.016)$ \\
\hline
\end{tabular}

*Adjusted by gender, age and number of chronic disease.

Australian population, found the worst HRQoL situations, using the SF-36, on ex-smokers, in dimensions of physical functioning, role physical, pain, general health and vitality, comparing with never smokers. Gulliford et al. (2003) [20] found difference in the physical functioning mean scores, comparing non-smokers with exsmokers; and the research by Laaksonen (2006) [21] presented difference only in pain dimension. Results from other studies showed similarity in comparing the quality of life of ex-smokers with non-smokers [17] [22]. It is also important to emphasize that longitudinal studies have found an increase in the HRQoL, in individuals who stopped smoking compared with those who still smoke [18] [19] [30] [31].

Analyzing the degree of nicotine dependence, assessed with the Fagerström test, it is possible to observe rising negative associations, of smokers compared with nonsmokers, rising according to the increase in the dependence level, which is in accordance with other studies [19] [21] [23] [24]. In this study, the associations can be observed mainly in the mental component scales with large differences among the mean scale scores. GuiterrezBedmar et al. (2009) [19] found differences in the mean scores in the fields of role-emotional and mental health, comparing with individuals who smoke less than 15 cigarettes per day with those who do not smoke, and the differences increase, with gradient, in individuals who smoke 15 to 24 cigarettes and 25 or more, impacting the physical functioning, general health, vitality and mental health dimensions. Besides the strong association with the MCS and its respective scales, the impact of smoking, considering heavy dependence, deserves attention on the pain scale, because it presents a high and significant association compared to non-smokers, which is in accordance with the study by Wilson et al. (1999) [23].

Considering the gender, some peculiarities were found in the results. The condition of current smokers showed a greater association with HRQL among females. The worse quality of life in women is observed on the scales of pain, general health, vitality, role-emotional and mental health aspects, besides the MCS. Among men, however, the associations were present in three scales and the MCS. It is important to consider that, in this pop- 
ulation, the highest percentage of former smokers is observed in the male population and in this case, it is possible that those who should present a deteriorated quality of life already have quit smoking and are no longer present among the smokers. A study conducted with a representative sample of the Finnish [22] population, evaluated quality of life using the 15D instrument, and found that male smokers are in worse HRQoL on 9 of 15 of the instrument scales, compared with those who never smoked, while the worst situations on women were observed in 6 scales.

The male individuals who quit smoking are in worse situations, compared with those who never smoked, in the MCS and on the general health, vitality and mental health scales. It is possible that individuals have quit smoking due to health problems and chronic disease, and these problems heavily interfere in the quality of life and in the health status [17]. In this study, in higher percentage, the ex-smokers (23.1\%) and smokers (24.9\%) have 2 or more chronic diseases. Analyses were controlled by number of diseases in an attempt to minimize this confounding factor, although the severity of the disease has not been considered.

In the female population, however, women who quit smoking are at similar situations to those who never smoked, in the crude and adjusted analysis, according with the study by Sarna et al. (2008) [16], conducted with data from the Nurse's Health Study (NHS), which has not found or found weak associations between exsmokers and never smokers, in the female population under 55 years old. Studies on the association of smoking with HRQoL, by gender are scarce, making it difficult to compare the results of this study.

Some limitation should be considered. The cross-sectional design does not allow detecting causes but, associations. On one hand, smoking can lead to an impact on health and in the HRQoL. On the other hand, individuals may be smokers due to low mental health conditions, considering that the study indicates the major associations of smoking in the mental component of the quality of life and health. Another limitation is the difficulty in evaluating the former smoker who may have quit due to the occurrence of disease. In this sense his health state may already be deteriorated, mainly because of the disease, making it difficult to verify the impact of quitting smoking.

According to main results of this study, the smoker individuals have the lower SF-36 score mean in bodily pain, general health, vitality, role-emotional, social functioning, mental health, and the MCS. Ex-smokers are with the lower score mean in vitality, mental health and MCS. According to nicotine dependence, the lower scores was observed in social functioning, mental health and MCS in the mild dependence category; in general health, vitality, mental health and MCS in the moderate nicotine dependence; and bodily pain, vitality, roleemotional, mental health and MCS, in heavy dependence, comparing with never smokers. According gender, the male population shows the lower score mean among smokers and ex-smokers, in general health, vitality, mental health and MCS. Female smokers show the lower score mean in bodily pain, general health, vitality, role-emotional, and MCS. Association among smokers and never smokers were not found on the female population.

The results of this research indicate a strong association of cigarette smoking with worst HRQoL conditions, reinforcing the importance of strategic policies against smoking and avoiding the rise of cigarette marketing. The associations were stronger in relation to the mental component of health, both in male and in female populations. The mental health scale of the SF-36 encompasses mainly the aspects of nervousness, depression, discouragement and happiness, as well as social and emotional aspects, in relation to daily life activities. Studies have increasingly shown that optimism, life satisfaction, happiness are associated with reduced incidence of disease, disability and mortality [32] [33], and at greater engagement in better health behaviors [34] [35]. It is important to give due importance to smoking individuals, because in worse mental health conditions, they may be vulnerable to greater tobacco consumption and increasing nicotine dependence, besides having greater difficulties to quitting smoking.

Special attention must also be spent to male ex-smokers, considering the strong associations in this segment of the population. The dimension of vitality deserves attention by the frequent associations with high magnitude. This scale considers both physical and mental aspects of health, addressing questions about desire, energy, tiredness, exhaustion [36]. Although no significant associations between smoking and physical functioning and role physical scales have been observed in the adjusted analyzes, the decreased vitality in smokers and exsmokers may indicate low physical functions.

Studies on HRQoL and self-reported health status are important in so far as provide information about health, considering its various dimensions [7]. The impact of smoking on disease occurrence and mortality is evident [1] [2], and the knowledge about the association of smoking with the different dimensions of health can contribute for understanding and monitoring the damage of tobacco in the self-reported physical conditions, in the well- 
being and the social relations of the population.

\section{Acknowledgements}

The authors are grateful to the CNPq (n 409747/2006-8) for financing this research (ISA-Camp 2008) and for the productivity scholarship provided to M. B. A. Barros and also to the Brazilian Ministry of Health and the Campinas Health Department for financial support to carry out the survey (Partnership Unicamp/Funcamp/SMS No 4300).

\section{References}

[1] WHO (World Health Organization) (2009) Global Health Risks: Mortality and Burden of Disease Attributable to selected Major Risks. WHO, Geneva.

[2] WHO (World Health Organization) (2010) Global Status Report on Non Communicable Diseases, 2010. WHO, Geneva.

[3] WHO (World Health Organization) (2011) WHO Report on the Global Tobacco Epidemic, 2011: Warning about the Dangers of Tobacco. WHO, Geneva.

[4] Brasil. Ministério da Saúde. Secretaria de Vigilância em Saúde. Departamento de Análise de Situação de Saúde (2011) Plano de ações estratégicas para o enfrentamento das doenças crônicas não transmissíveis (DCNT) no Brasil 2011-2022/ Ministério da Saúde. Secretaria de Vigilância em Saúde. Departamento de Análise de Situação de Saúde. Ministério da Saúde, Brasília.

[5] Brasil. Ministério da Saúde. Secretaria de Vigilância em Saúde. Secretaria de Gestão Estratégica e Participativa (2011) VIGITEL Brasil 2010: Vigilância de fatores de risco e proteção para doenças crônicas por inquérito telefônico. Ministério da Saúde, Brasília.

[6] Silva, G.A., Valente, J.G. and Malta, D.C. (2011) Trends in Smoking among the Adult Population in Brazilian Capitals: A Data Analysis of Telephone Surveys from 2006 to 2009. Revista Brasileira de Epidemiologia, 14, 103-114. http://dx.doi.org/10.1590/S1415-790X2011000500011

[7] Ware Jr., J.E., Kosinski, M., Bjorner, J.B., Turner-Bowker, D.M., Gandek, B. and Maruish, M.E. (2007) User’s Manual for the $36 \mathrm{v} 2{ }^{\circledR}$ Health Survey. 2nd Edition, Quality Metric Incorporated, Lincoln.

[8] Almeida-Filho, N. (2011) O que é Saúde? Editora Fiocruz, Rio de Janeiro.

[9] Lima, M.G., Barros, M.B.A. and Alves, M.C.G.P. (2012) Happiness in the Elderly: An Edipemiological Aproach in the ISA-Camp 2008 Study. Cadernos de Saúde Pública, 28, 2280-2292.

[10] Ciconelli, R.M., Ferraz, M.B., Santos, W., Meinão, I. and Quaresma, M.R. (1999) Tradução para a língua portuguesa e validação do questionário genérico de avaliação de qualidade de vida SF-36 (Brasil SF-36). Revista Brasileira de Reumatologia, 39, 143-150.

[11] McDowell, I. (2006) Measuring Health: A Guide to Rating Scales and Questionnaires. 3nd Edition, Oxford University Press, Inc., New York. http://dx.doi.org/10.1093/acprof:oso/9780195165678.001.0001

[12] Fryback, D.G. (2010) Measuring Health-Related Quality of Life. Workshop on Advancing Social SCIENCE Theory: The Importance of Common Metrics. The National Academies, Division of Behavioral and Sciences and Education. Washington DC.

[13] Lyons, R.A., Lo, S.V. and Littlepage, B.N.C. (1994) Perception of Health amongst Ever-Smokers and Never-Smokers: A Comparison Using the SF-36 Health Survey Questionnaire. Tobacco Control, 3, 213-215. http://dx.doi.org/10.1136/tc.3.3.213

[14] Woolf, S.H., Rothemich, S.F., Johnson, R.E. and Marsland, D.W. (1999) Is Cigarette Smoking Associated with Impaired Physical and Mental Functional Status? A Office-Based Survey of Primary Care Patients. American Journal of Preventive Medicine, 17, 134-137. http://dx.doi.org/10.1016/S0749-3797(99)00060-4

[15] Mulder, I., Tijhuis, M., Smit, H.Á. and Kromhout, D. (2001) Smoking Cessation and Quality of Life: The Effect of Amount of Smoking and Time since Quitting. Preventive Medicine, 33, 653-660. http://dx.doi.org/10.1006/pmed.2001.0941

[16] Sarna, L., Bialous, S.A., Cooley, M.E., Jun, H. and Feskanich, D. (2008) Impact of Smoking and Smoking Cessation on Health-Related Quality of Life in Women in the Nurses' Health Study. Quality of Life Research, 17, 1217-1227. http://dx.doi.org/10.1007/s11136-008-9404-8

[17] Lima, M.G., Barros, M.B.A., César, C.L.G., Carandina, L., Goldbaum, M. and Alves, M.C.G.P. (2011) Health-Related Behavior and Quality of Life among the Elderly: A Population-Based Study. Revista de Saúde Pública, 45, 845-893. http://dx.doi.org/10.1590/S0034-89102011000300006 
[18] Mitra, M., Chung, M., Wilber, N. and Walker, D.K. (2004) Smoking Status and Quality of Life. A Longitudinal Study among Adults with Disabilities. American Journal of Preventive Medicine, 27, 258-260.

[19] Guitérrez-Bedmar, M., Seguí-Gómez, M., Gómez-Gracia, E., Bes-Ratrollo, M. and Martínez-González, M.A. (2009) Smoking Status, Changes in Smoking Status and Health-Related Quality of Life: Findings from the SUN ("Seguimiento Universidad de Navarra”) Cohort. International Journal of Environmental Research and Public Health, 6, 310-320. http://dx.doi.org/10.3390/ijerph6010310

[20] Gulliford, M.C., Sedgwick, J.E.C. and Pearce, A.J. (2003) Cigarette Smoking, Health Status, Socio-Economic Status and Access to Health Care in Diabetes Mellitus: A Cross-Sectional Survey. BMC Health Services Research, 3, 4. http://dx.doi.org/10.1186/1472-6963-3-4

[21] Laaksonen, M., Rahkonen, O., Martikainen, P., Karvonen, S. and Lahelma, E. (2006) Smoking and SF-36 Health Functioning. Preventive Medicine, 42, 206-209. http://dx.doi.org/10.1016/j.ypmed.2005.12.003

[22] Heikkinen, H., Jallinoja, P., Saarni, S.I. and Patja, K. (2008) The Impact of Smoking on Health-Related and Overall Quality of Life: A General Population Survey in Finland. Nicotine \& Tobacco Research, 10, 1199-1107. http://dx.doi.org/10.1080/14622200802163142

[23] Wilson, D., Parsons, J. and Wakefield, M. (1999) The Health-Related Quality-of-Life of Never Smokers, Ex-Smokers, and Light, Moderate, and Heavy Smokers. Preventive Medicine, 29, 139-144. http://dx.doi.org/10.1006/pmed.1999.0523

[24] Vogl, M., Wenig, C.M., Leidl, R. and Pokhrel, S. (2012) Smoking and Health-Related Quality of Life in English General Population: Implications for Economic Evaluations. BMC Public Health, 12, 203. http://dx.doi.org/10.1186/1471-2458-12-203

[25] Ware, J.E. and Kosinski, M. (2001) SF-36 Physical \& Mental Health Summary Scales: A Manual for Users of Version 1, 2nd Edition. Quality Metric Incorporated, Lincoln.

[26] Meneses-Gaya, I.C., Zuardi, A.W., Loureiro, S.R. and Crippa, J.A.S. (2009) As propriedades psicométricas do teste de Fagerstrom para dependência de nicotina. Jornal Brasileiro de Pneumologia, 35, 73-82. http://dx.doi.org/10.1590/S1806-37132009000100011

[27] Cayuela, A., Rodríguez-Domínguez, S. and Otero, R. (2007) Deteriorated Health-Related Quality of Life in Healthy Male Smokers. Archivos de Bronconeumología, 43, 59-63.

[28] Díez, J.M., Maestu, L.P., Peña, M.M.E., Barrera, V.H., Garrido, P.C., Walther, L.A.A. and García, R.J. (2010) Relationship between Tobacco Consumption and Health-Related Quality of Life in Adults Living in a Large Metropolitan Area. Lung, 188, 393-399. http://dx.doi.org/10.1007/s00408-010-9256-1

[29] Hays, R.D., Smith, A.W., Reeve, B.B., Spritzer, S.E.M. and Clauser, S.B. (2008) Cigarette Smoking and Health-Related Quality of Life Medical Beneficiaries. Health Care Financing Review, 29, 57-67.

[30] Tillmann, M. and Silcock, J. (1997) A Comparison of Smoker's and Ex-Smoker's Health-Related Quality of Life. Journal of Public Health Medicine, 19, 268-273. http://dx.doi.org/10.1093/oxfordjournals.pubmed.a024629

[31] Piper, M.E., Kenford, S., Fiore, M.C. and Baker, T.B. (2012) Smoking Cessation and Quality of Life: Changes in Life Satisfaction over 3 Years Following a Quit Attempt. Annals of Behavioral Medicine, 43, 262-270. http://dx.doi.org/10.1007/s12160-011-9329-2

[32] Kubzansk, L.D., Sparrow, D., Vokonas, P. and Kawachi, I. (2001) Is the Glass Half Empty or Half Full? A Prospective Study of Optimism and Coronary Heart Disease in the Normative Aging Study. Psychosomatic Medicine, 63, 910-916. http://dx.doi.org/10.1097/00006842-200111000-00009

[33] Kubzansk, L.D. and Thuston, R.C. (2007) Emotional Vitality and Incident Coronary Heart Disease. Archives of General Psychiatry, 64, 1393-401. http://dx.doi.org/10.1001/archpsyc.64.12.1393

[34] Collins, A.L., Goldman, N. and Rodriguez, G. (2008) Is Positive Well-Being Protective of Mobility Limitations among older Adults? Journals of Gerontology Series B: Psychological Sciences and Social Sciences, 63, 321-327.

[35] Baruth, M., Lee, D.C., Sui, X., Church, T.S., Marcus, B.H., Wicox, S. and Blair, S.N. (2011) Emotional Outlook on Life Predicts Increases in Physical Activity among Initially Inactive Men. Health Education \& Behavior, 38, 150-158. http://dx.doi.org/10.1177/1090198110376352

[36] Ware, J.E. and Kosinsk, M. (2000) SF-36 Health Survey: Manual and Interpretation Guide. 2a. Edição. Quality Metric Incorporated, Lincoln. 
Scientific Research Publishing (SCIRP) is one of the largest Open Access journal publishers. It is currently publishing more than 200 open access, online, peer-reviewed journals covering a wide range of academic disciplines. SCIRP serves the worldwide academic communities and contributes to the progress and application of science with its publication.

Other selected journals from SCIRP are listed as below. Submit your manuscript to us via either submit@scirp.org or Online Submission Portal.
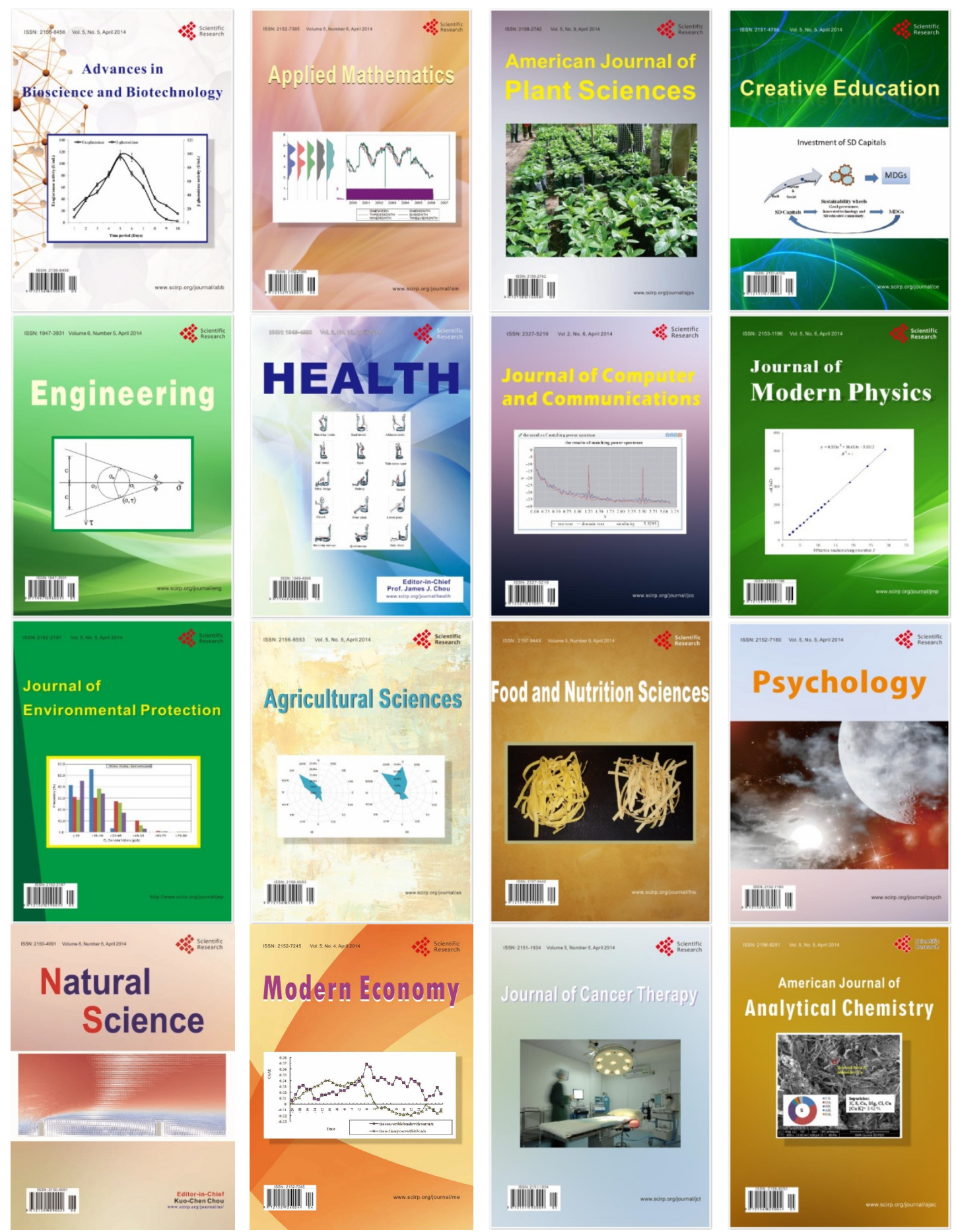